\title{
Genetic and morphological characterisation of a new species of the genus Hysterothylacium (Nematoda) from Paralichthys isosceles Jordan, 1890 (Pisces: Teleostei) of the Neotropical Region, state of Rio de Janeiro, Brazil
}

\author{
Marcelo Knoff ${ }^{1}$, Nilza Nunes Felizardo 1 , Alena Mayo Iñiguez ${ }^{2}{ }^{+}$, Arnaldo Maldonado Jr ${ }^{3}$, \\ Eduardo José L Torres ${ }^{4}$, Roberto Magalhães Pinto', Delir Corrêa Gomes ${ }^{1}$
}

${ }^{1}$ Laboratório de Helmintos Parasitos de Vertebrados ²Laboratório de Genética Molecular de Microorganismos ${ }^{3}$ Laboratório de Mamíferos Silvestres Reservatórios, Instituto Oswaldo Cruz-Fiocruz, Av. Brasil 4365, 21045-900 Rio de Janeiro, RJ, Brasil ${ }^{4}$ Laboratório de Biologia de Helmintos Otto Wucherer, Instituto de Biofísica Carlos Chagas Filho, Universidade Federal do Rio de Janeiro, Rio de Janeiro, RJ, Brasil

Taking into account the difficulties of taxonomic identification of larval anisakid nematodes based on morphological characters, genetic analyses were performed, together with those usually applied, in order to identify anisakid larvae found in the flounder Paralichthys isosceles from the littoral of the state of Rio de Janeiro, Brazil. The analysis of 1,820 larvae revealed a new species, similar to Hysterothylacium MD, Hysterothylacium 2, Hysterothylacium $K B$ and Hysterothylacium sp regarding the absence of the larval tooth, an excretory pore situated below the nerve ring level, and slender lateral alae. Moreover, the new species differs from Hysterothylacium fortalezae and Hysterothylacium reliquens with regard to the number and size of spines present on the tail end and from Hysterothylacium patagonicus by the absence of interlabia. The maximum parsimony and neighbour joining tree topologies based on the $18 \mathrm{~S}$ ribosomal DNA gene, complete internal transcribed spacer region and cytochrome oxidase 2 (COII) gene demonstrated that the Brazilian larvae belong to Raphidascarididae and represent a unique genetic entity, confirmed as a new Hysterothylacium species. Furthermore, the new species presents COII genetic signatures and shares polymorphisms with Raphidascarididae members. This is the first description of a new anisakid species from Brazil through the integration of morphological and molecular taxonomy data.

Key words: Raphidascarididae - Hysterothylacium - new species - morphology - molecular taxonomy

The study of larval anisakids infecting fishes raises many doubts related to their taxonomic identification and, thus, promotes the proposal of different nomenclatures, thereby increasing difficulties in obtaining their proper specific diagnosis. More than 60 species of the genera Hysterothylacium (Raphidascarididae Hartwich, 1954, sensu Fagerholm, 1991), which parasitize estuarial, freshwater and marine fishes, have been described around the world (Gopar-Merino et al. 2005). However, Hysterothylacium larvae suffered from indefinite taxonomy and are frequently mistaken with the Contracaecum genus (Lopes et al. 2011). In South American countries, larvae and adults of Hysterothylacium sp. have already been reported from Ecuador, Hysterothylacium corrugatum (Deardorff \& Overstreet 1981), Argentina, Hysterothylacium rhamdiae (Brizzola \& Tanzola 1995), Hysterothylacium patagonense (Moravec et al. 1997), Hysterothylacium aduncum (Incorvaia \& Hernández 2006) and from Chile, Hysterothylacium geshei (Torres et

Financial support: CNPq, FIOCRUZ

AMI and RMP are CNPq research fellows.

+ Corresponding author: alena@ioc.fiocruz.br

Received 10 May 2011

Accepted 9 August 2011 al. 1998), Hysterothylacium winteri (Torres \& Soto 2004) and $H$. aduncum (Torres et al. 2010). In Brazil, nematode adults of Hysterothylacium fortalezae (Klein 1973) and Hysterothylacium reliquens (Norris \& Overstreet 1975) were also recovered from teleosteans on the northeastern coast (Guimarães \& Cristofaro 1974, Deardorff \& Overstreet 1980). However, a number of Hysterothylacium sp. larvae have already been reported in 28 teleostean fish species from the littoral of the state of Rio de Janeiro (RJ) (Tavares \& Luque 2006). In the same region, Hysterothylacium sp. larvae were reported as the most prevalent anisakid nematode in Pagrus pagrus, a teleostean fish with significant commercial value (Saad \& Luque 2009).

Anisakiasis is considered a zoonosis that can affect humans after the ingestion of raw, poorly cooked or smoked fish meat infected with $\mathrm{L}_{3}$ larvae. Yagi et al. (1996) reported a case of human infection from Japan due to the ingestion of a fish parasitized with $H$. aduncum (Rudolphi, 1802). Until now, no cases of anisakiasis infection have been reported in Brazil. Overstreet and Meyer (1981) described haemorrhagic lesions and eosinophilia caused by Hysterothylacium larvae type MB, recovered from Paralichthys lethostigma, in a rhesus monkey experimental animal model. Recently, pathological alterations caused by Hysterothylacium larvae were observed in Paralichthys isosceles on the southeastern Brazilian coast (Felizardo et al. 2009b). These Hysterothylacium larvae were found parasitiz- 
ing different sites, including musculature and ovaries, with high prevalence. However, morphological analysis, with approaches including epidemiological and zoonotic aspects, revealed the necessity of adopting additional methodologies to permit a more reliable taxonomic identification of these Brazilian larvae.

Genetic and morphological analyses have been utilised in the present investigation, aiming at the proper identification of Hysterothylacium larvae parasitizing specimens of $P$. isosceles captured in the littoral of RJ.

\section{MATERIALS AND METHODS}

Studied material - From October 2006-March 2008, 1,820 larvae of anisakids of the genus Hysterothylacium were recovered from 60 specimens of the flounder $P$. isosceles Jordan, 1890, captured in the littoral of the munici-

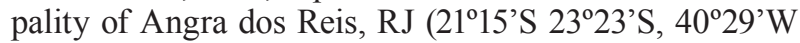
$\left.44^{\circ} 28^{\prime} \mathrm{W}\right)$. For morphological analysis, nematodes were fixed, clarified and preserved in accordance with Eiras et al. (2006). The taxonomic identification followed Peter and Maillard (1988), Incorvaia and Díaz de Astarloa (1998), Timi et al. (2001), Bicudo et al. (2005) and Felizardo et al. (2009a). Measurement ranges are in millimetres, with means in parentheses unless otherwise indicated. The nematode larvae reserved for molecular procedures were collected alive and free in the intestine, then were rinsed in a $0.65 \% \mathrm{NaCl}$ solution, observed under a stereomicroscope and preserved at $-20^{\circ} \mathrm{C}$ until DNA extraction.

Differential interference contrast (DIC) - Samples were clarified and photographed using an Axiophot Zeiss with micrographic system in a DIC apparatus (Zeiss, Germany).

Scanning electron microscopy - Samples fixed in $70 \%$ ethanol were dehydrated in an ethanol series $\left(100^{\circ}\right.$ $\mathrm{GL}), \mathrm{CO}_{2}$ critical-point dried, coated in gold and examined and photographed using a scanning electron microscope (JEOL SM-25 SII and Zeiss 962) under an accelerating voltage of 15 kvolts.

Statistical analysis - Pearson's correlation coefficient $(r)$ was applied to correlate the total length of the parasites with the biometry of their internal organs to determine the central tendency and dispersion of the measurements in order to ensure that the sample represents the population of larvae $\left(\mathrm{L}_{3} / \mathrm{L}_{4}\right)$. A t test with a $5 \%$ level of significance was used to determine the correlation coefficient (Serra-Freire 2002).

Deposit of the studied material - Representative specimens were deposited in the Helminthological Collection of the Oswaldo Cruz Institute-Oswaldo Cruz Foundation (CHIOC-Fiocruz).

Genetic analysis - Eleven Hysterothylacium larvae were washed with phosphate buffered saline and homogenised in liquid nitrogen for DNA extraction. DNA was extracted individually using a QIAamp ${ }^{\circledR}$ DNA Mini Kit (Qiagen) following the manufacturer's protocol with modifications, as described by Iñiguez et al. (2011). Polymerase chain reaction (PCR) targeting the $18 \mathrm{~S}$ ribosomal DNA (rDNA) gene, the complete internal transcribed spacer (ITS) region and the cytochrome c oxidase subunit II (cox2) gene were performed. The $18 \mathrm{~S}$ rDNA gene $(\sim 1,500$ bp) was amplified using the primers SSU-A (forward; 5'AAAGATTAAGCCATGCATG-3') and 18P (reverse; 5'TGATCCWKCYGCAGGTTCAC-3') (Dorris et al. 2002) and the following PCR conditions: $10 \mathrm{mM}$ Tris- $\mathrm{HCl}(\mathrm{pH}$ 8.0), $50 \mathrm{mM} \mathrm{KCl}, 2.5 \mathrm{mM} \mathrm{MgCl}, 0.2 \mathrm{mM}$ of each dNTP, $250 \mathrm{ng}$ of each primer, 1.5 U Platinum Taq Polymerase (Invitrogen) and 25-50 ng of genomic DNA in a volume of $50 \mu \mathrm{L}$. The reactions were subjected to an initial cycle of $5 \mathrm{~min}$ at $96^{\circ} \mathrm{C}$, followed by 40 cycles of $96^{\circ} \mathrm{C}$ for $30 \mathrm{~s}$, $60^{\circ} \mathrm{C}$ for $30 \mathrm{~s}$ and $72^{\circ} \mathrm{C}$ for $1 \mathrm{~min} 50 \mathrm{~s}$ in a programmable thermal controller (Mastercycler ep system, Eppendorf). Products were electrophoresed through $1.2 \%$ agarose gels and visualised using ethidium bromide staining. The ITS region ( 1,000 bp) was amplified using NC5 (forward; 5'CACCAACTCTTAAAATTATC-3') and NC2 (reverse; 5'- TTTTCTAGTTATATAGATTGRTTTYAT-3') (Zhu et al. 1999) and the PCR and electrophoresis conditions described above. The cox 2 gene fragment (629 bp) was amplified using 210 (forward; 5'-GTAGGTGAACCTGCGGAAGGATCATT-3') and 211 (reverse; 5'-TTAGTTTCTTTTCCTCCGCT-3') (Nadler \& Hudspeth 2000) and $10 \mathrm{mM}$ Tris- $\mathrm{HCl}$ (pH 8.0), $50 \mathrm{mM} \mathrm{KCl,} 2.5 \mathrm{mM} \mathrm{MgCl}_{2}$, $0.2 \mathrm{mM}$ of each dNTP, $300 \mathrm{ng}$ of each primer, $1.5 \mathrm{U}$ Platinum Taq Polymerase and 25-50 ng of genomic DNA, in a volume of $50 \mu \mathrm{L}$. The reactions were subjected to an initial cycle of $5 \mathrm{~min}$ at $96^{\circ} \mathrm{C}$, followed by 40 cycles of $96^{\circ} \mathrm{C}$ for $40 \mathrm{~s}, 45^{\circ} \mathrm{C}$ for $40 \mathrm{~s}$ and $72^{\circ} \mathrm{C}$ for $40 \mathrm{~s}$ in programmable thermal controller. Both strands of the Hysterothylacium PCR products were directly sequenced using the BigDye Terminator v. 3.1 Cycle Sequencing Kit (Applied Biosystems, USA) with a 3730 Automated DNA Sequencer (Applied Biosystems, USA).

The sequences were analysed using a global Basic Local Alignment Search Tool search (National Center for Biotechnology Information database) and BioEdit v7.0.4.1 (Department of Microbiology, North Carolina State University, USA). Genetic distance [p-distance, Kimura 2 parameters (K2P)], neighbour joining (NJ) $\mathrm{K} 2 \mathrm{P}$ and maximum parsimony (MP) trees were estimated using Molecular Evolutionary Genetics Analysis v. 4.0 software by bootstrap procedures $(2,000$ replicates $)$ (Tamura et al. 2007). All Hysterothylacium sp. sequences of $18 \mathrm{~S}$ rDNA, ITS and cox 2 available on the GenBank database were used in the analysis (February 2011). cox2 gene sequences were translated using the invertebrate mitochondrial translation code and the cytochrome oxidase 2 (COII) protein thus produced was examined for genetic signatures using GeneDoc software v. 2.6 .002 (ps.edu/ biomed/genedoc). The new Hysterothylacium sp. Brazilian sequences were deposited into the GenBank database with accessions JF718550 and JF730199-JF730214.

\section{RESULTS}

\section{Hysterothylacium deardorffoverstreetorum sp. nov.} (Figs 1-3)

Description - Description based on 54 third-stage larvae: cuticle with lateral alae extending along the body with a wedge-shaped support, devoid of basal extension. Anterior extremity with a dorsal and two poorly developed ventrolateral lips (Fig. 3A). Cephalic papil- 


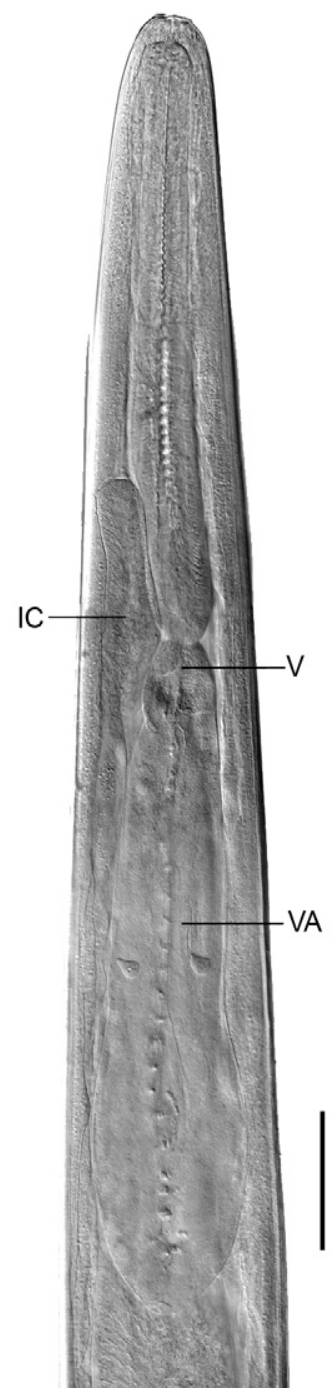

Fig. 1: Hysterothylacium deardorffoverstreetorum sp. nov., photomicrograph of anterior portion of a fourth stage larva by differential interference contrast. IC: intestinal cecum; V: ventriculus; VA: ventricular appendix. Bar $=200 \mu \mathrm{m}$.

lae (Fig. 3A), two pairs in the dorsal lip together with a large papilla and a pair in each ventrolateral lip. Boring tooth absent (Figs 1, 3A). Excretory pore opening below the nerve ring (Fig. 3C, D). Ventriculus nearly spherical (Fig. 1). Ventricular appendix twice as long as the oesophagus (Fig. 1). Intestinal caecum present (Fig. 1). Tail conical, mucron present (Figs 2, 3B). Description based on 50 fourth-stage larvae: morphological characteristics similar to those present in third-stage larvae were observed, except for the more developed lips (Fig. $3 \mathrm{~A}$ ) and the presence of a caudal multispinous process responsible for the cactus-tail format in the former. Additional morphological data and drawings, including anterior portion, posterior end and cross section, are in Felizardo et al. (2009a), as well as the parasitological indexes of prevalence, mean intensity, mean abundance and range of infection. The third-stage and fourth-stage

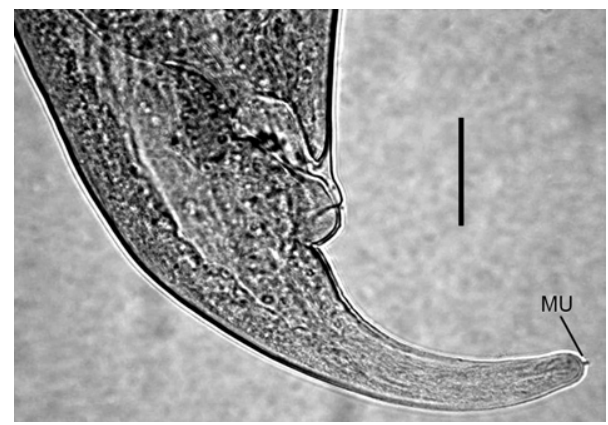

Fig. 2: Hysterothylacium deardorffoverstreetorum sp. nov., photomicrograph of posterior end by differential interference contrast. MU: mucron on the posterior end of third stage larva. Bar $=50 \mu \mathrm{m}$.
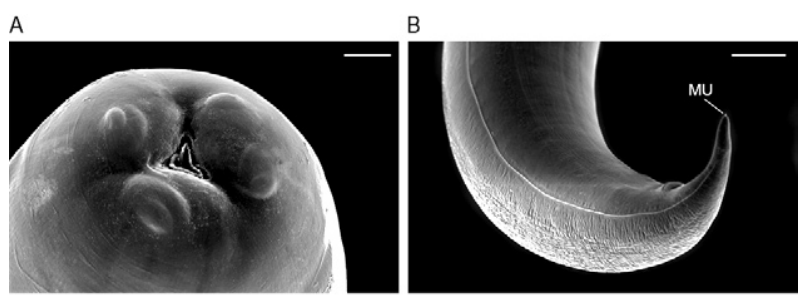

C
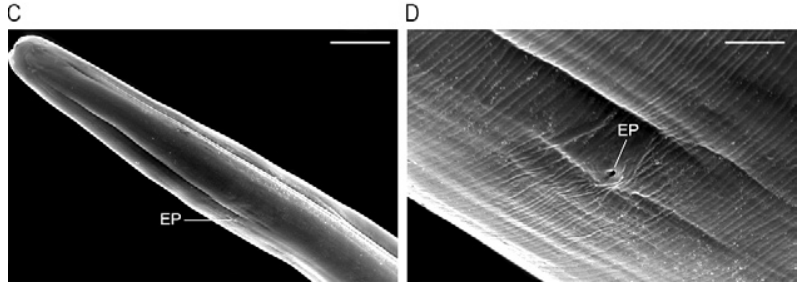

Fig. 3: Hysterothylacium deardorffoverstreetorum sp. nov., photomicrographs of third stage larva by scanning electron microscopy. A: anterior end, frontal view; B: mucron (MU); C: anterior portion, local of excretory pore (EP); D: detail of EP. Bars $=10 \mu \mathrm{m}$ (A, D), $50 \mu \mathrm{m}$ (B) and $100 \mu \mathrm{m}(\mathrm{C})$.

larvae (measurements based on 1,820 specimens): total length 3.62-16.7 (10.1), width 0.11-0.40 (0.25). Oesophagus 0.23-1.16 (0.69) in length, 0.04-0.19 (0.12) in width. Ventriculus 0.05-0.15 (0.10) in length. Ventricular appendix 0.35-1.37 (0.86). Intestinal caecum 0.05-0.32 (0.18). Nerve ring and excretory pore situated $0.12-0.46(0.29)$ and 0.25-0.46 (0.36), respectively, from the anterior end. Tail 0.10-0.32 (0.20). Mucron 3-8 $\mu \mathrm{m}(5 \mu \mathrm{m})$.

Type-host - P. isosceles Jordan, 1890.

Sites of infection - Abdominal cavity, abdominal musculature, stomach, stomach mucosa, mesentery, intestine, heart serosa, kidney serosa, liver serosa, ovary, ovary serosa and spleen serosa.

\section{Type-locality - Municipality of Angra dos Reis.}

Type data and depository - The holotype and paratypes are deposited in the CHIOC-Fiocruz under the registration 37523a, holotype and 37523b-e, 35771, paratype. The accessions in GenBank are JF718550 and JF730199-JF730214. 
Etymology - The Latin name deardorffoverstreetorum is given after Drs Thomas L Deardorff and Robin M Overstreet, for their contributions to the knowledge of this group of nematodes.

Remarks - Based on the statistical analysis that determined the external validity of the sample, it can be confirmed that, with $5 \%$ probability of error type I, there are significant correlations regarding the following: (i) the body length of the parasite compared with the length of the ventriculus $\left(r=0.6904\right.$ in $\mathrm{L}_{4}, 0.6184$ in $\left.\mathrm{L}_{3}\right)$ and the intestinal caecum $\left(r=0.7207\right.$ in $\mathrm{L}_{4}, 0.5415$ in $\mathrm{L}_{3}$ ), (ii) the oesophagus length compared to the length of the ventriculus $\left(r=0.6701\right.$ in $\mathrm{L}_{4}$ and 0.7462 in $\left.\mathrm{L}_{3}\right)$, intestinal caecum $\left(r=0.6690\right.$ in $\mathrm{L}_{4}, 0.6532$ in $\left.\mathrm{L}_{3}\right)$ and ventricular appendix $\left(r=0.6089\right.$ in $\mathrm{L}_{4}, 0.7792$ in $\left.\mathrm{L}_{3}\right)$, (iii) length of the ventriculus and intestinal caecum $\left(r=0.6872\right.$ in $\mathrm{L}_{3}$ and 0.4949 in $\left.\mathrm{L}_{4}\right)$. The correlation of the ventriculus length with the ventricular appendix was significant in $\mathrm{L}_{4}(r=0.7578)$ and accentuated in $\mathrm{L}_{3}(r=0.8122)$; conversely, the correlation of the body length and the length of the oesophagus was accentuated in $\mathrm{L}_{4}(r=0.8614)$ and significant in $\mathrm{L}_{3}(r=0.6981)$. There was an outstanding correlation regarding the body length of the fish and the oesophagus length in the $\mathrm{L}_{4}$ larvae $(r=0.4664)$, which was unimportant in the case of larval $\mathrm{L}_{3}$ nematodes $(r=0.2356)$. Also, the correlation of the length of the ventricular appendix with the intestinal caecum was considerable $(r=0.5068$ in $\mathrm{L}_{4}, r=0.5759$ in $\mathrm{L}_{3}$ ), as well as with the body length of the parasite $\left(r=0.5942\right.$ in $\left.\mathrm{L}_{4}\right)$ and remarkable in $\mathrm{L}_{3}(r$ $=0.7223)$. The other correlations, although inconsistent $(0.16<r<0.30)$, are not to be disregarded $(0<r<0.15)$. Therefore, the results of statistical analysis showed that $\mathrm{L}_{3}$ and $\mathrm{L}_{4}$ larvae belong to the same species and that observed variations are related to the vital conditions to which the populations were submitted in the considered environment.

Genetic analysis - Samples of Hysterothylacium sp. nov. yielded the expected PCR products of the three genetic regions analysed. The $18 \mathrm{~S}$ rDNA sequences $(1,479$ bp) were identical and matched the $18 \mathrm{~S}$ rDNA Hysterothylacium sp. sequences available, with 99\% similarity to Hysterothylacium pelagicum (U94375) and $98 \%$ similarity to $H$. reliquens (U94376) and $H$. fortalezae (U94374). Nematodes studied here revealed low genetic distance values between other Raphidascarididae spp studied so far, including Raphidascaris acus (p-distance $=0.01)$, Iheringascaris inquies $(\mathrm{p}$-distance $=0.03)$ and Goezia pelagia $(\mathrm{p}$-distance $=0.06)$. The MP tree showed that the new species of the genus Hysterothylacium and the other anisakid species are in a unique cluster characterising the Raphidascarididae, with a high bootstrap value (Fig. 4). The genus Hysterothylacium was not monophyletic, with a clade containing $H$. pelagicum, $R$. acus, I. inquies and G. pelagia and another clustering $H$. reliquens and $H$. fortalezae (Fig. 4).

The ITS sequences (867 bp) from the new species revealed six ITS haplotypes with a mean genetic distance of 0.003 (p-distance $=0.001-0.007)$. The MP and NJ trees were inferred based on ITS (758 bp) using 18 Ascaridida ITS sequences, including all available Hys-

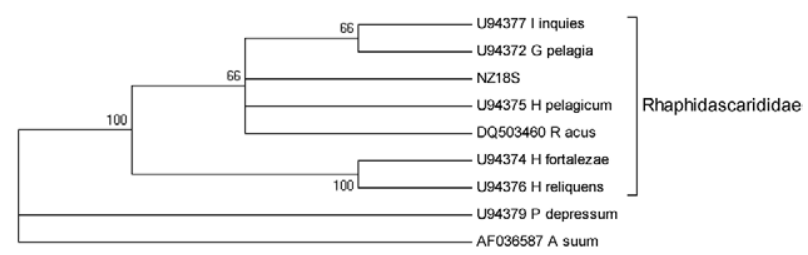

Fig. 4: maximum parsimony tree inferred from $18 \mathrm{~S}$ ribosomal DNA sequence data from Hysterothylacium deardorffoverstreetorum sp. nov. and other Raphidascarididae spp studied. Phylogenetic analyses were conducted in MEGA4. H. deardorffoverstreetorum sp. nov. is named as NZ 18S. GenBank accession and the species name are shown. Ascaris suum and Porrocaecum depressum are outgroups.

terothylacium species: H. aduncum, Hysterothylacium auctum, Hysterothylacium bidentatum, Hysterothylacium (Contracaecum) muraenesoxi and Pseudoterranova decipiens as an outgroup. The MP tree revealed that all $H$. deardorffoverstreetorum sp. nov. grouped in a monophyletic clade with a high bootstrap value (99\%) (Fig. 5). Specimens were included in a main cluster (bootstrap $=89 \%$ ) with $H$. muraenesoxi and $R$. acus species. Another well-supported and large cluster (98\%) is formed by Hysterothylacium species alone. Contracaecum and Raphidascaris species (except R. acus) are in particular clusters basal to the Hysterothylacium groups. The NJ (K2P) tree showed similar topology, with sequences grouped in a strongly supported monophyletic clade (bootstrap $=100 \%$ ), but the Raphidascaris cluster is placed in the largest Hysterothylacium group (data not shown).

The cox2 sequences (506 bp) of the new species have a mean genetic distance of $0.03(0.01 \mathrm{SE})$ and the K2P distance vs. $H$. fortalezae was K2P $=0.18$ (0.01 SE). K2P genetic distances of $H$. deardorffoverstreetorum sp. nov. vs. $H$. reliquens and $H$. pelagicum were higher, with 0.21 (0.01 SE) and 0.23 (0.01 SE), respectively. The tree topologies generated using both MP and NJ methods allocated the new species in a monophyletic clade with a well-supported bootstrap value (99\%) and not closely related to other Hysterothylacium sp. (Fig. 6) (NJ tree, data not shown). On the MP tree, genus-specific clusters with moderate and strong support were delineated in the genera Anisakis, Ascaris, Hysterothylacium (H. reliquens and H. pelagicum) and Toxocara. The same genus-specific clades, plus a Contracaecum clade (bootstrap $=68 \%$ ), were observed in the NJ analysis (bootstrap > 70\%), although the Hysterothylacium clade was poorly supported (data not shown). Protein in silico analysis of the new species revealed a 168 amino acids COII sequence from positions 51-218 (reference Ascaris suum, Genbank X54253) (Fig. 7). The comparison of 20 anisakid COII sequences demonstrated that members of Raphidascarididae contain the combined genetic signatures V69, M77, I80 and N92, except for the highly polymorphic $H$. fortalezae (V69, I77, V80 and S92). The new Hysterothylacium specimens share the Raphidascarididae signatures, but also present two particular polymorphisms of isoleucine at positions I133 and I194, constituting genetic signatures (Fig. 7). Other COII genetic signatures, L171 and V232, were also found in Contracaecum and Toxocara species, respectively. 


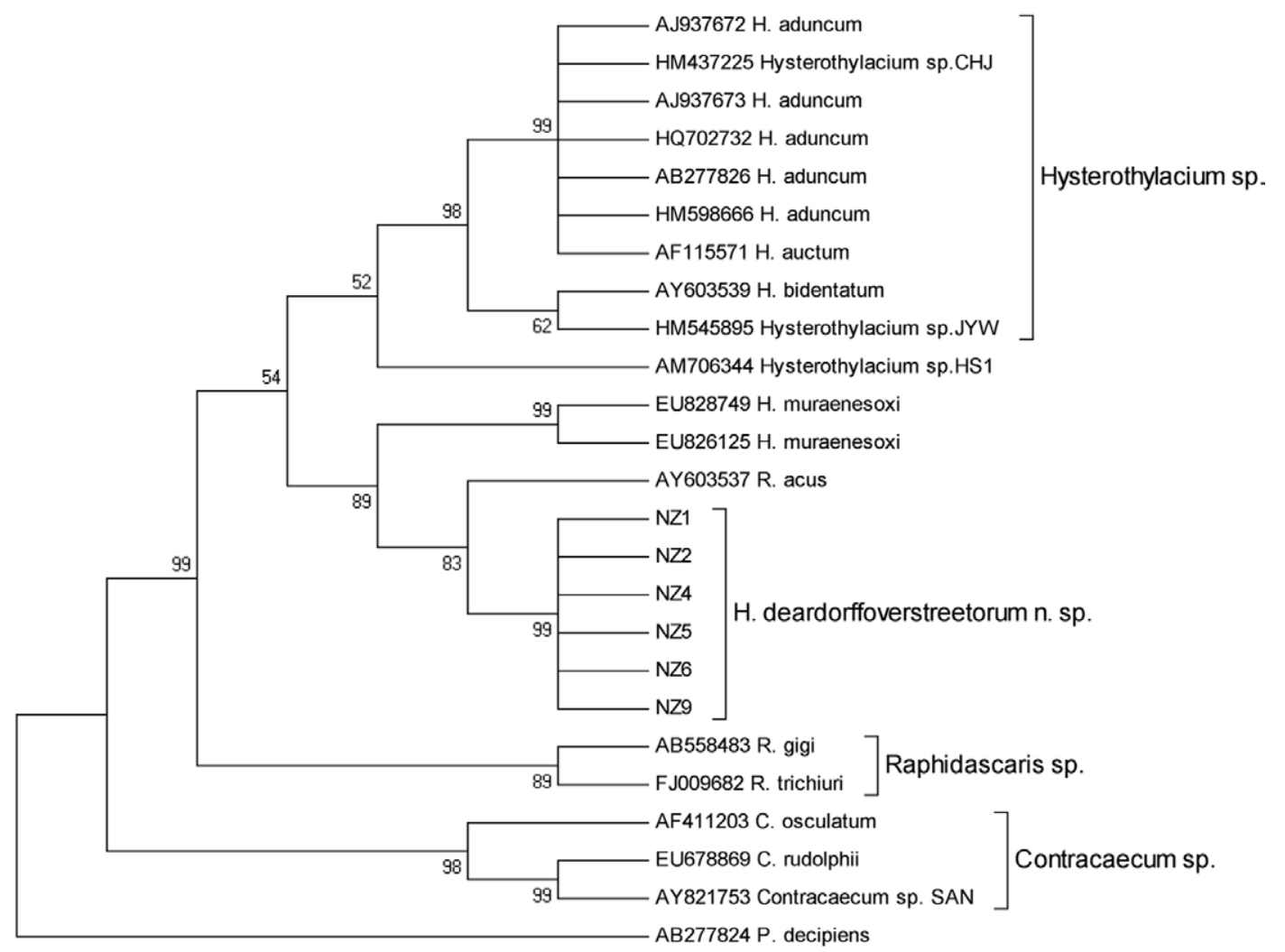

Fig. 5: maximum parsimony tree inferred from internal transcribed spacer (ITS) region sequence data from Hysterothylacium deardorffoverstreetorum sp. nov. and other Raphidascarididae spp studied. Phylogenetic analyses were conducted in MEGA4. Only ITS haplotypes from $H$. deardorffoverstreetorum sp. nov. sequences were represented. ITS haplotype sequence from NZ2 was identical to NZ3, NZ7-8 and NZ10-NZ11. GenBank accession and the species name are shown. Pseudoterranova decipiens is the outgroup taxa.

\section{DISCUSSION}

Larvae of Hysterothylacium recovered from $P$. isosceles are here described as a new species, taking into account the defined morphological characteristics of the species. These larvae are similar to Hysterothylacium MD of Deardorff and Overstreet (1981), Hysterothylacium 2 of Petter and Maillard (1988), Hysterothylacium KB of Petter and Sey (1997) and Hysterothylacium sp. of Pereira Jr et al. (2004) due to the absence of a larval tooth, an excretory pore located below the nerve ring and the presence of slender lateral alae, together with similarities related to the body size, oesophagus, intestinal caecum, ventricular appendix and rounded tail with mucron. Among the species reported in South America, the third and fourth-stage larvae presently studied and that were recovered from flounders in the Brazilian littoral differ from larvae of $H$. fortalezae (Klein 1973) by the absence of lateral alae in the cephalic region and the presence of six caudal spines and from specimens of $H$. reliquens (Norris \& Overstreet 1975), which present numerous spines in the posterior end of the tail (Deardorff \& Overstreet 1981). Also, considering the absence of interlabia, they differ from the fourth-stage larvae of $H$. patagonense (Moravec et al. 1997), which infect specimens of Percichthys trucha and from the larvae of $H$. winteri (Torres \& Soto 2004), in Eleginops maclovinus.
The structures that are present in the caudal tip of some species can change in the different stages $\left(\mathrm{L}_{3} \rightarrow\right.$ $\mathrm{L}_{4} \rightarrow$ adults). Thus, the $\mathrm{L}_{3}$ with mucron and the $\mathrm{L}_{4}$ with a spiny cluster differ from $\mathrm{L}_{3}$ and $\mathrm{L}_{4}$ larvae of $H$. fortale$z a e$, the former presenting six spines and the latter with a variation of 7-12 spines and from larvae of $H$. reliquens, which present the same caudal pattern until they develop into adults (Deardorff \& Overstreet 1980, 1981). These ontogenetic modifications have already been reported by Pereira Jr et al. (2004) and Felizardo et al. (2009a).

The above-mentioned morphological characteristics suggest that the larval forms of Hysterothylacium MD, Hysterothylacium 2, Hysterothylacium KB and Hysterothylacium $\mathrm{sp}$. should be identified as $H$. deardorffoverstreetorum sp. nov.

The molecular characterisation based on three genetic markers also supports the evidence of a new Hysterothylacium species. The $18 \mathrm{~S}$ rDNA gene of $H$. deardorffoverstreetorum $\mathrm{sp}$. nov. yielded a unique sequence that confirms the taxonomic position on Raphidascarididae. ITS and cox 2 genetic analyses provided strong evidence that this species is a unique genetic entity, characterising a new anisakid species. The phylogenetic tree topologies were in significant agreement, demonstrating that $H$. deardorffoverstreetorum sp. nov. represents a taxonomic unit genetically distant from other anisakids, 


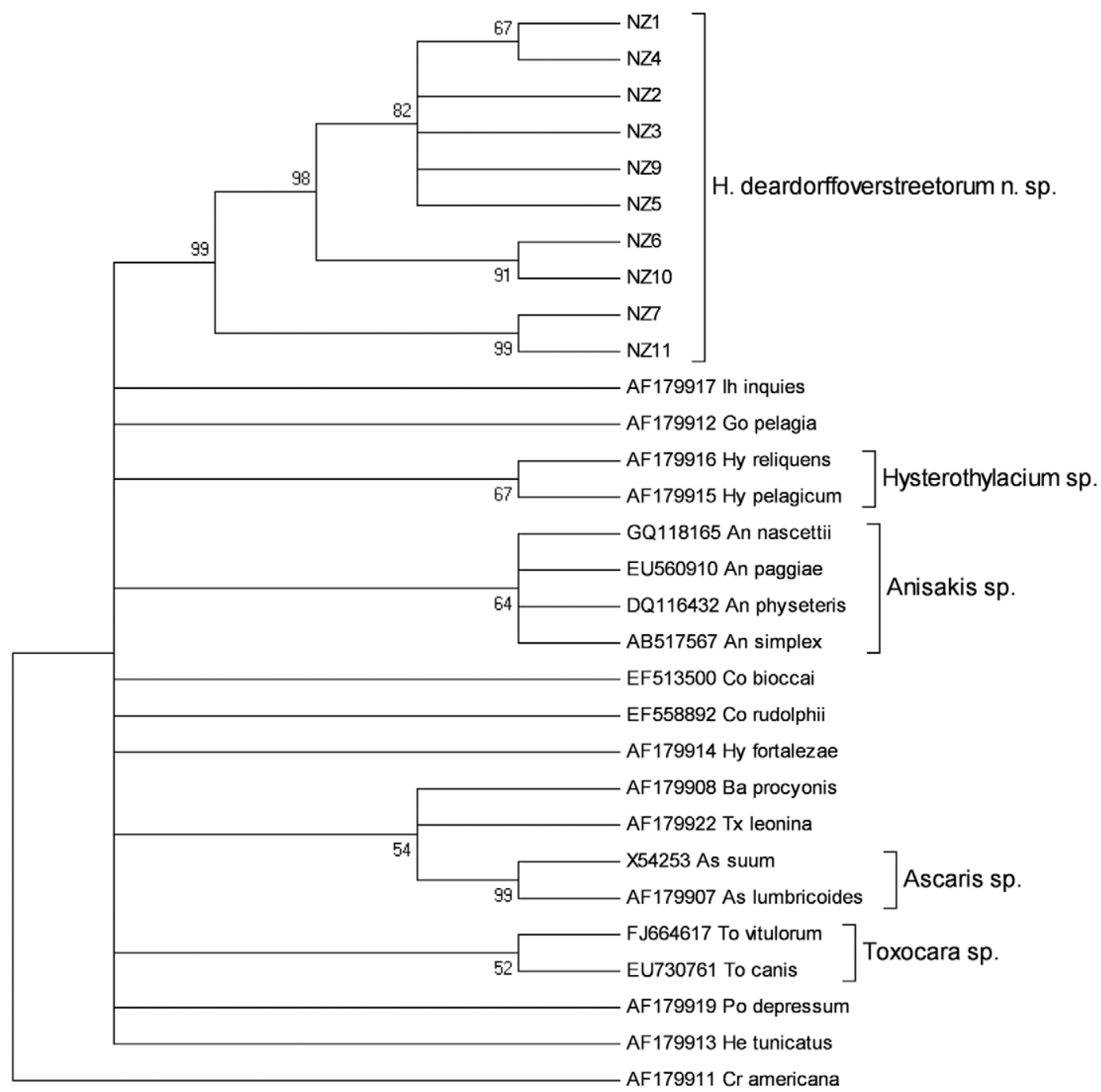

Fig. 6: maximum parsimony tree inferred from cytochrome c oxidase subunit II (cox2) gene sequence data from Hysterothylacium deardorffoverstreetorum sp. nov. and other Nematode spp studied. Phylogenetic analyses were conducted in MEGA4. H. deardorffoverstreetorum sp. nov. sequences are named as NZ1-NZ11. cox2 haplotype of NZ8 was identical to NZ3. GenBank accession and the species name are shown. Cruzia americana is the outgroup taxa.

even from other Hysterothylacium sp. In this regard, both genetic targets permitted the evaluation of all Hysterothylacium spp studied (H. aduncum, $H$. auctum, $H$. bidentatum, $H$. muraenesoxi, $H$. reliquens, $H$. fortalezae and $H$. pelagicum) and therefore confirm that the larvae do not belong to any Hysterothylacium sp. genetically described before. Concerning the relationships between congeners, $H$. deardorffoverstreetorum sp. nov., $H$. pelagicum and $R$. acus are in a polytomy on the 18S rDNA tree. Smythe et al. (2006) observed a similar 18S rDNA MP tree topology, with two clades for Hysterothylacium spp, one of which contained $H$. pelagicum, $R$. acus, $I$. inquies and $G$. pelagia. Interestingly, using ITS topologies, it was possible to verify two Hysterothylacium clusters, one of which grouped specimens of Hysterothylacium deardorffoverstreetorum sp. nov., H. muraenesoxi and a sequence of $R$. acus. ITS sequences of H. muraenesoxi are annotated in the GenBank database as Contracaecum muraenesoxi, which requires updating because $\mathrm{Li}$ et al. (2008) redescribed and proposed its synonymy. The presence of $R$. acus in the Hysterothylacium cluster could indicate a polyphyletic condition of the Raphidascaris group, as the well-supported clade of Raphidascaris sp. (Raphidascaris gigi and Raphidascaris trichiuri) is shaped and placed basal to the Hysterothylacium groups (MP), or in the largest Hysterothylacium clade (NJ). A misclassification of R. acus could be also a plausible explanation, as morphological characterisation or molecular analysis of this specimen (AY603537) is not available. The phylogenetic analysis obtained from the mitochondrial DNA (mtDNA) cox2 dataset clearly supports $H$. deardorffoverstreetorum $\mathrm{sp}$. nov. as an evolutionarily separate taxon, despite some intraspecific genetic heterogeneity. The use of cox 2 in this study corroborates the value of this genetic marker as a barcode for molecular taxonomy, allowing the 


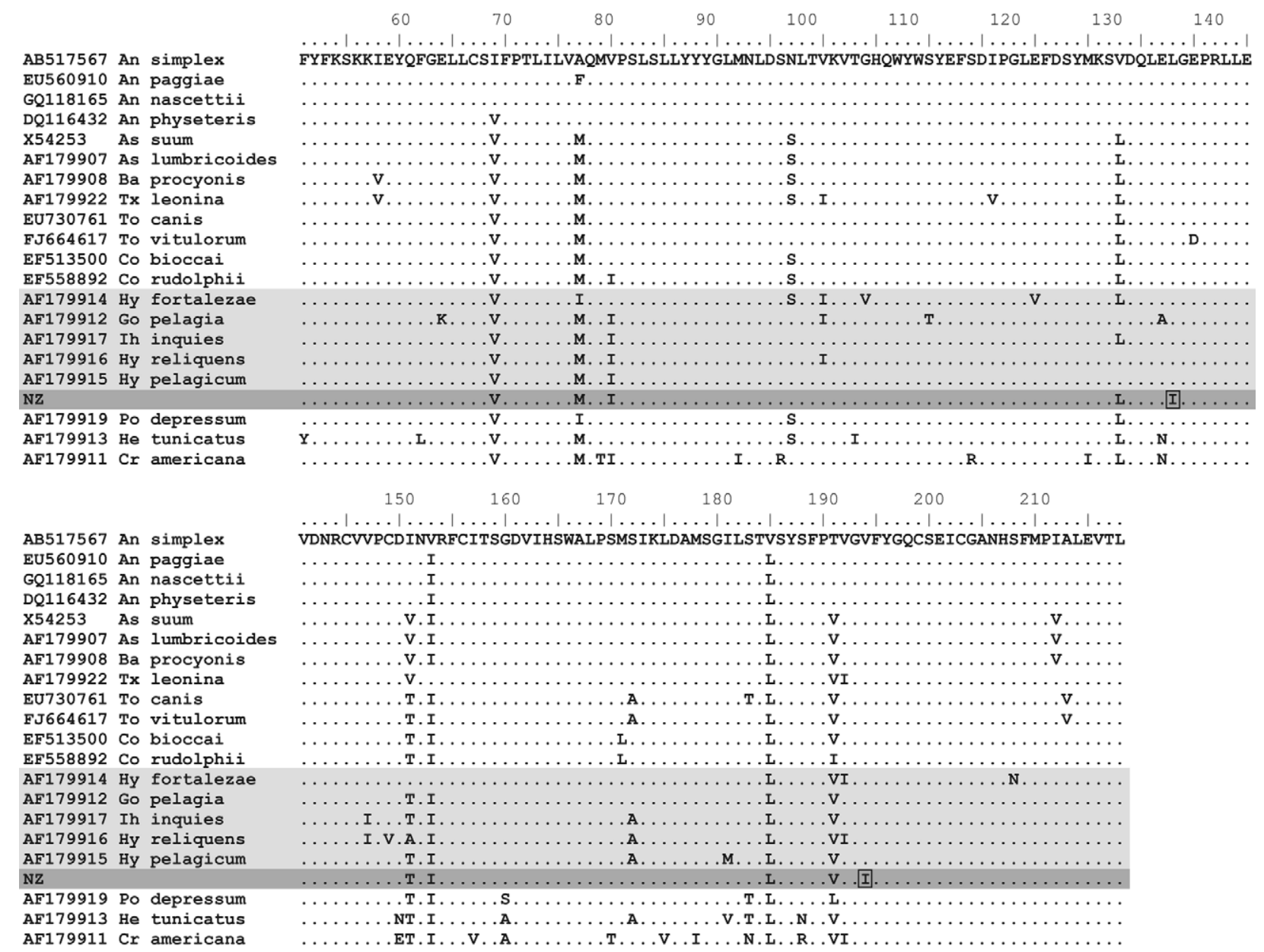

Fig. 7: alignment of amino acids sequence of cytochrome oxidase 2 (COII) from Hysterothylacium deardorffoverstreetorum $\mathrm{sp}$. nov. and other Nematode spp studied. Translation code 5: mitochondrial invertebrate. GenBank accession and the name of the species are shown. Points indicate the identity with Anisakis simplex reference sequence. Raphidascarididae sequences are in light grey and NZ represents $H$. deardorffoverstreetorum sp. nov. sequence in hard grey. COII genetic signatures of $H$. deardorffoverstreetorum sp. nov. are in box.

identification of presumed new or sibling species as demonstrated and proposed for anisakids nematode research (Valentini et al. 2006, Mattiucci et al. 2009). In addition, cox 2 gene analyses were in agreement with the observation that Hysterothylacium does not represent a monophyletic group. However, different from 18S rDNA topologies, the Hysterothylacium genus-specific cluster is formed by $H$. reliquens and $H$. pelagicum. Previous studies also reported these conflicting clades based on rDNA and mtDNA analyses, even when using a combined analysis including morphological traits (Nadler \& Hudspeth 2000). In this study, based on the new data from both anisakid specimens and genetic markers (ITS), the unsolved molecular taxonomy of the Hysterothylacium group is evident, suggesting a polyphyletic group condition. In silico COII protein analysis further supported the taxonomic problem of the Hysterothylacium group, as the set of genetic signatures identified the Raphidascarididae species and excluded the $H$. fortalezae member. The presence of Raphidascarididae COII signatures in H. deardorffoverstreetorum sp. nov., as well as the detection of particular genetic signatures, provided additional and significant evidence of a new anisakid nematode species.

\section{ACKNOWLEDGEMENTS}

To Dr Nicolau Maués da Serra Freire, from National Reference Laboratory of Vectors of Rickettsial diseases/IOC/ Fiocruz, for the statistic analysis, Milena Mota and Koko Otsuki, from Laboratory of Molecular Genetics of Microorganisms/IOC-Fiocruz, for their technical assistance, to PDTIS/ Fiocruz, for the genomic platform nucleotide sequencing, and Heloisa Nogueira Diniz, from Service Production and Processing of Images/IOC/Fiocruz.

\section{REFERENCES}

Bicudo AJA, Tavares LER, Luque JL 2005. Metazoários parasitos da cabrinha Prionotus punctatus (Bloch, 1793) (Osteichthyes: Triglidae) do litoral do Estado do Rio de Janeiro, Brasil. Rev Bras Parasitol Vet 14: 27-33.

Brizzola SM, Tanzola RD 1995. Hysterothylacium rhamdiae sp. n. (Ascaridoidea: Anisakidae) from a neotropical catfish, Rhamdia sapo (Pisces: Pimelodidae). Mem Inst Oswaldo Cruz 90: 349-352. 
Deardorff TL, Overstreet RM 1980. Review of Hysterothylacium and Iheringascaris (both previously = Thynnascaris) (Nematoda: Anisakidae) from the Northern Gulf of Mexico. Proc Helminthol Soc Wash 93: 1035-1079.

Deardorff TL, Overstreet RM 1981. Larval Hysterothylacium (= Thynnascaris) (Nematoda: Anisakidae) from fishes and invertebrates in the Gulf of Mexico. Proc Helminthol Soc Wash 48: 113-126.

Dorris M, Viney ME, Blaxter ML 2002. Molecular phylogenetic analysis of the genus Strongyloides and related nematodes. Int $J$ Parasitol 32: 1507-1517.

Eiras JC, Takemoto RM, Pavanelli JC 2006. Métodos de estudo e técnica laboratoriais em parasitologia de peixes, 2 nd ed., Eduem, Maringá, 199 pp.

Fagerholm HP 1991. Systematic implications of male caudal morphology in ascaridoid nematode parasites. Syst Parasitol 19: 215-228.

Felizardo NN, Knoff M, Pinto RM, Gomes DC 2009a. Larval anisakid nematodes of the flounder, Paralichthys isosceles Jordan, 1890 (Pisces: Teleostei) from Brazil. Neotrop Helminthol 3: 57-64.

Felizardo NN, Menezes RC, Tortelly R, Knoff M, Pinto RM, Gomes DC 2009b. Larvae of Hysterothylacium sp. (Nematoda: Anisakidae) in the sole fish Paralichthys isosceles Jordan, 1890 (Pisces: Teleostei) from the littoral of the State of Rio de Janeiro, Brazil. Vet Parasitol 166: 175-177.

Gopar-Merino L, Osorio-Sarabia D, Garcia-Prieto L 2005. A new species of Hysterothylacium (Nematoda: Anisakidae) parasite of Ariopsis guatemalensis (Osteichthyes: Ariidae) from Tres Palos lagoon, Mexico. J Parasitol 91: 909-914.

Guimarães JF, Cristofaro R 1974. Contribuição ao estudo da fauna helmintológica de peixes do estado da Bahia. Atas Soc Biol 17: 81-85.

Incorvaia IS, Díaz de Astarloa JM 1998. Estudio preliminar de las larvas (Nematoda: Ascaridida) parásito de Paralichthys orbignyanus (Valenciennes, 1839) y Paralichthys patagonicus (Pisces: Pleuronectiformes) Bol Chil Parasitol 53: 38-42.

Incorvaia IS, Hernández DR 2006. Nematodes parásitos como indicadores biológicos de Macruronus magellanicus. INIDEP Inf Tec 61: 1-24.

Iñiguez AM, Carvalho VL, Motta MR, Pinheiro DC, Vicente AC 2011. Genetic analysis of Anisakis typica (Nematoda: Anisakidae) from cetaceans of the northeast coast of Brazil: new data on its definitive hosts. Vet Parasitol: 178: 293-299.

Klein VLM 1973. Helmintos parasitos das espécies Scomberomorus cavalla (Cuvier) e Scomberomorus maculatus (Mitchill) do litoral cearense. Contracaecum fortalezae sp. n. (Nematoda, Ascaridoidea). Mem Inst Oswaldo Cruz 71: 199-202.

Li L, Xu Z, Zhang L 2008. Redescription of three species of Hysterothylacium (Nematoda: Anisakidae) from marine fishes from the Yellow Sea, China, with the synonymy of Hysterothylacium muraenesoxin (Luo, 1999). Zootaxa 1878: 55-67.

Lopes LP, Pimpao DM, Takemoto RM, Malta JC, Varella AM 2011. Hysterothylacium larvae (Nematoda, Anisakidae) in the freshwater mussel Diplodon suavidicus (Lea, 1856) (Mollusca, Unioniformes, Hyriidae) in Aripuana River, Amazon, Brazil. J Invertebr Pathol 106: 357-359.

Mattiucci S, Paoletti M, Webb SC 2009. Anisakis nascettii n. sp. (Nematoda: Anisakidae) from beaked whales of the southern hemisphere: morphological description, genetic relationships between congeners and ecological data. Syst Parasitol 74: 199-217.

Moravec F, Uruwa S, Coria CO 1997. Hysterothylacium patagonense n. sp. (Nematoda: Anisakidae) from freshwater fishes in Patagonia, Argentina, with a key to the species of Hysterothylacium in American freshwater fishes. Syst Parasitol 36: 31-38.
Nadler SA, Hudspeth DSS 2000. Phylogeny of the Ascaridoidea (Nematoda: Ascaridida) based on three genes and morphology: hypotheses of structural and sequence evolution. J Parasitol 86: 380-393.

Norris DE, Overstreet RM 1975. Thynnascaris reliquens sp. n. and T. habena (Linton, 1900) (Nematoda: Ascaridoidea) from fishes in the northern Gulf of Mexico and eastern U.S. Seaboard. J Parasitol 61: 330-336.

Overstreet RM, Meyer GW 1981. Hemorragic lesion in the stomach of rhesus monkey caused by a piscine ascaridoid nematode. J Parasitol 67: 226-235.

Pereira Jr J, Almeida FM, Morais NCM, Vianna RT 2004. Hysterothylacium sp. larva (Nematoda: Anisakidae) in Micropogonias furnieri (Sciaenidae) from Rio Grande do Sul cost, Brazil. Atlantica (Rio Grande) 26: 55-60.

Petter AJ, Maillard C 1988. Larves d'ascarides parasites de poissons en Méditerranée occidentale. Bull Mus Hist Nat 10: 347-369.

Petter JA, Sey O 1997. Nematode parasites of marine fishes from Kuwait with a description of Cucullanus trachinoti $\mathrm{n}$. sp. from Trachinotus blochi. Zoosystema 19: 35-59.

Saad CD, Luque JL 2009. Larval Anisakidae in musculature of Pagrus pagrus from the State of Rio de Janeiro, Brazil. Rev Bras Parasitol Vet 18: 71-73.

Serra-Freire NM 2002. Planejamento e análise de pesquisas parasitológicas, EdUFF, Niterói, 195 pp.

Smythe AB, Sanderson MJ, Nadler SA 2006. Nematode small subunit phylogeny correlates with alignment parameters. Syst Biol 55: 972-992

Tamura K, Dudley J, Nei M, Kumar S 2007. MEGA4: Molecular Evolutionary Genetics Analysis (MEGA) sofware version 4.0. Mol Biol Evol 24: 1596-1599.

Tavares LER, Luque JL 2006. Sistemática, biologia e importância em saúde coletiva de larvas de Anisakidae (Nematoda: Ascaridoidea) parasitas de peixes ósseos marinhos do Estado do Rio de Janeiro, Brasil. In AT Silva-Souza, Sanidade de organismos aquáticos no Brasil 15, ABRAPOA, Maringá, 387 pp.

Timi JT, Sardella NH, Navone GT 2001. Parasitic nematodes of Engraulis anchoita Hubbs et Marini, 1935 (Pisces, Engraulidae) off the Argentine and Uruguayan coasts, South West Atlantic. Acta Parasitol 46: 186-193.

Torres P, Andrade P, Silva R 1998. On a new species of Hysterothylacium (Nematoda: Anisakidae) from Cauque mauleanum (Pisces: Atherinidae) by brightfield and scanning electron microscopy. Mem Inst Oswaldo Cruz 93: 745-752.

Torres P, Quintanilla JC, Rozas M, Miranda P, Ibarra R, San Martin MF, Raddatz B, Wolter M, Villegas A, Canobra C, Hausdorf M, Silva R 2010. Endohelminth parasites from salmonids in intensive culture from southern Chile. J Parasitol 96: 669-670.

Torres P, Soto MS 2004. Hysterothylacium winteri sp. n. (Nematoda: Anisakidae), a parasite of Chilean rock cod, Eleginops maclovinus (Perciformes: Eleginopidae), from south Chile. Folia Parasitol 51: 55-60.

Valentini A, Mattiucci S, Bondanelli P, Webb SC, Mignucci-Giannone AA, Colom-Llavina MM, Nascetti G 2006. Genetic relationships among Anisakis species (Nematoda: Anisakidae) inferred from mitochondrial cox 2 sequences and comparison with allozyme data. J Parasitol 92: 156-166.

Yagi K, Nagasawa K, Ishikura H, Nagagawa A, Sato N, Kikuchi K, Ishikura K, Ishikura H 1996. Female worm Hysterothylacium aduncum excreted from human: a case report. J Parasitol 45: 12-23.

Zhu X, Chilton NB, Jacobs DE, Boes J, Gasser RB 1999. Characterisation of Ascaris from human and pig hosts by nuclear ribosomal DNA sequences. Int J Parasitol 29: 469-78. 